\title{
Awareness, knowledge and Practice about Injection Safety among Nurses Working in Medical and Surgical Department at Assiut Ministry Health Hospitals
}

\author{
Shaimaa Fathy Fakery ${ }^{1}$, Magda Ahmed Mohammed ${ }^{2}$, Shaymaa Sayed Khalil ${ }^{3}$. \\ 1. B.SC. Nursing , Faculty of Nursing, Assiut University, Assiut, Egypt. \\ 2. Professor, Adult Nursing Department, Faculty of Nursing, Assiut University, Assiut, Egypt. \\ 3. Lecturer, Adult Nursing Department, Faculty of Nursing, Assiut University, Assiut, Egypt.
}

\begin{abstract}
Aim of the Study: To assess awareness, knowledge and practice about injection safety among nurses working in medical and surgical units at Assiut ministry of health hospitals. Patients and method: Descriptive cross-sectional research design was utilized in this study. Sample: 500 male and female nurses. The study was conducted in medical and surgical units at five hospitals in Assiut ministry of health hospitals. Tools: Two tools used in the study :Tool (I) Self-administered questionnaire sheet consisted of three parts: (1) demographic characteristics of the nurses, (2) immunization and needle stick incidence among nurses, (3) assessment of nursing awareness and knowledge about injection safety. Tool (II): Observational check-list sheet. Results: Nearly all nurses $98.6 \%$ had a good awareness level and more than half had a satisfactory knowledge score and good practice score (69.4\% and 63.4\% respectively) regarding injection safety. Conclusion: Majority of the nurses had a good level of awareness regarding injection safety but less than half of them had unsatisfactory knowledge and the practical injection safety precautions were not followed properly. Recommendation: Nurses in need for in-service training programs and refreshing courses to improve their awareness and knowledge about injection safety which will reflect on their practice while working with patients.
\end{abstract}

\section{Key words: Injection Safety, Nurses, Awareness, Knowledge \& Practice.}

\section{Introduction}

Injection safety was defined as practices that intended to prevent transmission of infectious diseases between one patient and another, or between a patient and healthcare provider, and also to prevent harms such as needle-stick injuries (NSIs), and to ensure safe environment for providers, patients and community through appropriate management of dangerous medical waste (Abdul Aziz et al., 2013).

Safe/unsafe injection: An injection was considered safe if it did not harm the recipient, did not expose the provider to any avoidable risks and did not result in waste that is dangerous for the providers, recipients and community. On the contrary, an injection was therefore considered unsafe if it harmed the recipient, exposed the provider to any avoidable risks and resulted in waste that was dangerous for the providers, recipients and community (Chowdhury et al., 2011).

Injection safety is not a high focus component of healthcare workers (HCWs) training (doctors, nurses, paramedical workers...etc.) and most of the understanding on injections is by the simple rule of on the job training. Therefore, if a wrong practice is adopted by the person who is followed by healthcare workers, all of them learn the same mistakes and thus the effects are multiplied manifold in actual practice. Therefore there is a need for a training module that can help address this most common intervention in healthcare (Njiru et al., 2013).
Unsafe injection practices are a major public health problem and can lead to the transmission of blood borne pathogens, including hepatitis B virus (HBV), hepatitis $\mathrm{C}$ virus (HCV) and human immunodeficiency virus (HIV).The prevalence of $\mathrm{HBV}$ and $\mathrm{HCV}$ in Egypt is high and unsafe injections transmit most of these infections. (Hanafi et al., 2011).

Nearly 22 million individuals are infected each year representing $33 \%$ of new HBV infections, $42 \%$ of new HCV infections and $2 \%$ of all new HIV infections that are attributable to unsafe injections. (Thrift et al., 2017)

The reasons and prevalence of unsafe injection practices differ all over the world, relying on huge number of factors; knowledge, awareness, socio culture, economics and legal factors. (Drechsel et al., 2015)

In general, unsafe injection practices include reusing injection syringes; administering unnecessary injections for those conditions for which oral medications are accessible and prescribed; accidental NSIs among health professionals while giving an injection; and improper handling and administration of the sharp wastes. (Tandon et al., 2017)

In hospitals, nurses are the first level of the staff in contact with the risk of infection from unsafe practices related to needles and sharps. They are expected to undertake activities related to patient care 
with the beginning of their clinical years, they lack experience and skill, therefore; at a higher risk of infection from unsafe practices related to needles and sharps (Wendland, 2012).

The injection procedures performed by the healthcare personnel at the selected facilities were observed to determine the magnitude and types of unsafe injection practices (AL-Rawajfah, 2016).

Safe collection of injection equipment requires the use of puncture-proof disposal containers. This limits the risk associated with recapping needles since they are disposed of immediately after use and encourages a safe working environment for healthcare providers. (Sam., 2016)

Nursing education, work experience, training on injection safety (universal precautions) and regular supervision had to increase level of awareness among nurses. (Martin et al., 2013)

\section{Significance of the study}

Injection is one of the key health care procedures used globally for administration of medicine; the practices of unsafe injection not only harm the patient but also carry out the risks to health care workers. From the researcher's clinical experience at ministry of health hospital it has been observed that nurses lack awareness and knowledge regarding safe injection practice that are reflected negatively on their practice.

\section{The Aim of the Study}

The aim of this study was to assess awareness, knowledge and practice on injection safety among nurses working in medical and surgical units at Assiut ministry of health hospitals.

\section{Research questions}

1. What is the awareness level of nurses about injection safety?

2. What are the practical nursing defects related to injection safety at Assiut ministry of health hospitals?

\section{Operational definition}

Awareness: knowledge and understanding in all aspect of injection safety as evaluated by receiving right answer to all the questions related to awareness in that topic.

\section{Sample \& Methods \\ Research desig:}

A descriptive cross-sectional study was conducted in this study.

\section{Setting}

The study was conducted in medical and surgical units at five Assiut ministry of health hospitals included: General Aleman Hospital, Assiut Fever Hospital, Chest hospital, General Assiut Hospital, Hospital of Ophthalmology.

\section{Sample}

A sample of 500 males \& female nurses working in medical and surgical units at Assiut ministry of health hospitals, included: (120) nurses working at General Aleman hospital, (96) at Assiut Fever hospital, (100) at Chest hospital, (105) at General Assiut hospital and hospital of Ophthalmology(79) nurses and are willing to participate in the study within seven months from the beginning of March to September, 2017.

Study tools

The following two tools were utilized to collect data in this study. They were developed by the researchers after extensive review of the relevant literature.

Tool I: Self-administrated questionnaire sheet

The aim of this tool was to assess nursing awareness and knowledge about injection safety, this tool consisted of three parts:

Part(1): Demographic characteristic of the nurses it included 10 items,: such as (age, sex, unite, marital status, residence, qualification, years of experiences and training courses received, immunization against hepatitis B, needle sticks injury in last 6 months and recording of needle stick injury).

Part (2): Immunization and needle stick incidence among nurses it included 3 items: (immunization against hepatitis B, needle stick injury in the last 6 months, recording of needle stick injury)

Part (3): Assessment of nursing awareness and Knowledge about injection safety: the aim of this part was to assess nurses' awareness and knowledge about injection safety.

Regarding awareness; included eleven questions for awareness: hand washing proceeding injection, use of gloves proceeding injection, appropriate disposal after use and ----etc.

Regarding knowledge; these parts included 6 questions: as(definition of Injection safety, definition of unsafe injection, diseases transmitted by NSI )

Scoring system:

Regarding awareness; scores assigned to each item were between 0 and 1 points as follows; (1=yes and $0=$ no).

According to range of total scores it was between ( 0 11 ), considering good awareness above $60 \%$ of the range of total score, nurses were classified as: good awareness if their total score was > 7, and were classified as poor awareness if their total score was $<7$.

Regarding knowledge; a 5-point Likert scale was used. Scores assigned to each item were between 0 and 3 points as follows; (poor, good, very good, and excellent). According to the range of total scores it was between (0-18), Considering satisfactory 
knowledge as $60 \%$ of the range of total score, nurses were classified as having satisfactory level of knowledge if their total score was $>11$, and were classified as having unsatisfactory level of knowledge if their total score was $<11$.

\section{Tool II: Observational check-list sheet}

The aim of this tool was to assess nurses' practice about injection safety.

It Included 18 items as (recapping of used needle with both hands, hand washing before and after administering injection)

\section{Scoring system}

That uses a 3-point Likert scale. Scores assigned to each item are between 0 and 2 points as follows; (not done, done incorrect, and done correct).

According to range of total scores lie between (0-36), considering good practice as: $70 \%$ of the range of total score, nurses were classified as: good practice if their total score was $>25$, and were classified as poor practice if their total score was $<25$.

\section{Methods}

- An official letter was issued from the Dean of the Faculty of Nursing to the Head of internal medicine department soliciting the necessary approval to conduct the present research after explaining the aim and nature of the study to them to obtain their cooperation.

- A review of national and international related literature in the various aspects of the problem using books, articles, periodicals, and magazines was done.

- Content validity of tools: was established by 5 expertise's of the medical surgical nursing at Assiut University who reviewed the tools of data collection for clarity, relevance, comprehensiveness, understanding, and applicability. Modifications were made accordingly, and then the tools were designed in their final format and tested.

- Reliability: was estimated by Cronbach test. The tools proved to be reliable at $(0.73,0.71$ and 0.81 respectively).

- A pilot study was carried out in April ,2017 that was conducted on $10 \%$ of the sample in the selected setting, it consisted of (50) nurses who were added to the study later as there were no modifications.

\section{Ethical consideration}

- Research proposal was approved by ethical committee of the faculty of nursing .

- Informed consent was taken from patient participating study, after explaining the nature and purpose of the study.

- Confidentiality and anonymity were being assured.

- Nurses were assured that, the data of his research will not be refused without second permission.
- Patients were informed that they refuse to participate and or withdraw from the study without any rational any time.

- Data Collection took one month for every hospital and collect date at the time of medication administration at the morning shift each day.

- Each nurse was observed directly by the researcher while performing routine injection to fill the observational check-list sheet (tool II).

- At this time all available nurses were observed and the researcher spent 20-30 minutes to complete the observation check-list while the nurses were performing the routine injection.

- At initial interview; the researcher introduced herself to initiate communication and explained the nature and purpose of the study.

- Nurses were asked to fill out the questionnaire sheet (tool I) to assess nurses`awareness and knowledge completely and truthfully. Nurses spent 10-15 minutes to complete it.

- The study was carried out at morning and afternoon shifts every day.

- Data were collected through the period from $1 / 3 / 2017$ to $1 / 9 / 2017$

- The questionnaire and observation check list sheets were entered into computer for data analysis by utilizing SPSS program.

\section{Statistical design}

The statistical Package for (SPSS) version (23) was used to analyze data. Descriptive statistics was used for the quantitative data in knowledge and awareness questionnaire and the demographic data. Descriptive statistics included: Frequencies, percentages and cross tabulation. The level of significance for this study was set at $(p=0.05)$ to detect any indication of differences found in the data available. 


\section{Results}

Part I:Description of the studied nurses characteristics.

Table (1): Distribution of demographic characteristics of the studied nurses $(n=500)$.

\begin{tabular}{|c|c|c|}
\hline Items & N. & $\%$ \\
\hline \multicolumn{3}{|l|}{ Age (years): } \\
\hline $20-30$ & 310 & 62 \\
\hline $30-40$ & 131 & 26.2 \\
\hline $40-65$ & 59 & 11.8 \\
\hline \multicolumn{3}{|l|}{ Sex: } \\
\hline Male & 60 & 12 \\
\hline Female & 440 & 88 \\
\hline \multicolumn{3}{|l|}{ Marital status: } \\
\hline Single & 109 & 21.8 \\
\hline Married & 380 & 76 \\
\hline Divorced & 5 & 1 \\
\hline Wooden & 6 & 1.2 \\
\hline \multicolumn{3}{|l|}{ Educational level: } \\
\hline Diploma & 200 & 40 \\
\hline Technical & 215 & 43 \\
\hline Baccalaureate & 85 & 17 \\
\hline \multicolumn{3}{|c|}{ Work Experience (In Years): } \\
\hline$<5$ & 205 & 41 \\
\hline $5-10$ & 128 & 25.6 \\
\hline$>10$ & 167 & 33.4 \\
\hline \multicolumn{3}{|c|}{ Injection safety training in last two year: } \\
\hline Yes & 382 & $\mathbf{7 6 . 4}$ \\
\hline No & 118 & 23.6 \\
\hline \multicolumn{3}{|l|}{ Infection control training: } \\
\hline Yes & 464 & 92.8 \\
\hline No & 36 & 7.2 \\
\hline Total & 500 & $\overline{100}$ \\
\hline
\end{tabular}

Table (2): Percentage distribution of immunization\& needle stick incidence for the studied nurses ( $n=500)$.

\begin{tabular}{|l|l|l|}
\hline \multicolumn{1}{|c|}{ Variables } & \multicolumn{1}{|l|}{ No } & $\%$ \\
\hline Immunization against hepatitis B & $\mathbf{4 3 4}$ & $\mathbf{8 6 . 8}$ \\
\hline Yes & 66 & 13.2 \\
\hline No & \multicolumn{2}{l|}{} \\
\hline Needle sticks injury in last 6 months & 109 & 21.8 \\
\hline Yes & $\mathbf{3 9 1}$ & $\mathbf{7 8 . 2}$ \\
\hline No & 149 & 29.8 \\
\hline Recording for those who have needle stick injury & $\mathbf{3 5 1}$ & $\mathbf{7 0 . 2}$ \\
\hline Yes & $\mathbf{5 0 0}$ & $\mathbf{1 0 0}$ \\
\hline No &
\end{tabular}


Part II: Nurses 'awareness regarding injection safety.

Table (3): Distribution of the studied nurses 'awareness level regarding injection safety $(n=500)$.

\begin{tabular}{|l|c|c|c|c|}
\hline \multirow{2}{*}{\multicolumn{1}{|c|}{ Awareness about }} & \multicolumn{2}{c|}{ Positive awareness } & \multicolumn{2}{c|}{ Negative awareness } \\
\cline { 2 - 5 } & $\mathbf{N .}$ & $\mathbf{\%}$ & $\mathbf{N}$. & $\mathbf{\%}$ \\
\hline 1-Avoid recapping of needles after use. & $\mathbf{4 4 1}$ & $\mathbf{8 8 . 2}$ & 59 & 11.8 \\
\hline 2-Hand washing proceeding injection. & 485 & $\mathbf{9 7}$ & 15 & 3 \\
\hline 3-Use of gloves proceeding injection. & 465 & $\mathbf{9 3}$ & 35 & 7 \\
\hline 4-Appropriate disposal after use. & 484 & $\mathbf{9 6 . 8}$ & 16 & 3.2 \\
\hline 5- Avoid bending of needles after use. & 475 & $\mathbf{9 5}$ & 25 & 5 \\
\hline 6- Avoid reuse of used syringes or needle. & 490 & $\mathbf{9 8}$ & 10 & 2 \\
\hline 7-Appropriate use of safety boxes. & 478 & $\mathbf{9 5 . 6}$ & 22 & 4.4 \\
\hline 8-Use of dry cotton for cleaning area. & 295 & $\mathbf{5 9}$ & 205 & 41 \\
\hline 9- Adequacy of safety box supply. & 420 & $\mathbf{8 4}$ & 80 & 16 \\
\hline 10-Regularity of safety box supply. & 409 & $\mathbf{8 1 . 8}$ & 91 & 18.2 \\
\hline 11- Collection of needle in safety box. & 448 & $\mathbf{8 9 . 6}$ & 52 & 10.4 \\
\hline Total & 500 & & & 100 \\
\hline
\end{tabular}

Part III: Nurses' knowledge regarding injection safety.

Table (4): Percentage distribution of the studied nurses 'knowledge regarding injection safety. $(n=500)$

\begin{tabular}{|l|c|c|c|c|c|c|c|c|}
\hline \multirow{2}{*}{\multicolumn{1}{|c|}{ Knowledge }} & \multicolumn{2}{|c|}{ Poor } & \multicolumn{3}{c|}{ Good } & \multicolumn{2}{c|}{ Very good } & \multicolumn{2}{c|}{ excellent } \\
\cline { 2 - 9 } & N. & $\mathbf{\%}$ & N. & $\mathbf{\%}$ & N. & $\mathbf{\%}$ & N. & \% \\
\hline Definition of Injection safety. & $\mathbf{2 6 9}$ & $\mathbf{5 3 . 8}$ & 85 & 17 & 125 & 25 & 21 & 4.2 \\
\hline Definition of unsafe injection. & $\mathbf{3 0 4}$ & $\mathbf{6 0 . 8}$ & 87 & 17.4 & 87 & 17.4 & 22 & 4.4 \\
\hline Diseases transmitted by NSI. & 163 & 32.6 & $\mathbf{2 0 2}$ & $\mathbf{4 0 . 4}$ & 121 & 24.2 & 14 & 2.8 \\
\hline Possible causes of NSI. & 197 & 39.4 & $\mathbf{2 0 5}$ & $\mathbf{4 1}$ & 94 & 18.8 & 4 & .8 \\
\hline Preventive measures from NSI. & 165 & 33 & $\mathbf{1 7 8}$ & $\mathbf{3 5 . 6}$ & 141 & 28.2 & 16 & 3.2 \\
\hline Measures to be taken after NSI. & $\mathbf{1 8 8}$ & $\mathbf{3 7 . 6}$ & 142 & 28.4 & 137 & 27.4 & $\mathbf{3 3}$ & $\mathbf{6 . 6}$ \\
\hline
\end{tabular}

Table (5): Distribution of nurses practice score regarding injection safety practice. $(n=500)$

\begin{tabular}{|c|c|c|c|c|c|c|}
\hline \multirow[t]{2}{*}{ Checklist items } & \multicolumn{2}{|c|}{ Done correct } & \multicolumn{2}{|c|}{ Done incorrect } & \multicolumn{2}{|c|}{ Not done } \\
\hline & N. & $\%$ & N. & $\%$ & N. & $\%$ \\
\hline 1-Wash hands before injection. & 66 & 13.2 & 163 & 32.6 & 271 & 54.2 \\
\hline 2-Wash hands after injection. & 118 & 23.6 & 264 & 52.8 & 118 & 23.6 \\
\hline 3-Wear gloves before injection. & 308 & 61.6 & 13 & 2.6 & 179 & 35.8 \\
\hline 4-Read the label over medication vial or ampoule. & 339 & 67.8 & 125 & 25 & 36 & 7.2 \\
\hline 5- Injections are prepared using aseptic technique. & 430 & 86 & 56 & 11.2 & 14 & 2.8 \\
\hline $\begin{array}{l}\text { 6-The rubber septum on a medication vial is a disinfected } \\
\text { with alcohol prior to piercing. }\end{array}$ & 40 & 8 & 25 & 5 & 435 & 87 \\
\hline 7-Aspirating drug from ampoule. & 51 & 10.2 & 11 & 2.2 & 438 & 87.6 \\
\hline 8 -Needles and syringes are used for only one patient. & 476 & 95.2 & 5 & 1 & 19 & 3.8 \\
\hline 9-Two hands recapping. & 275 & 55 & 19 & 3.8 & 206 & 41.2 \\
\hline $\begin{array}{l}\text { 10-Disinfection of area done by alcohol swab by using } \\
\text { inward to outward direction. }\end{array}$ & 120 & 24 & 138 & 27.6 & 242 & $\overline{48.4}$ \\
\hline 11-Medication vials are entered with a new needle. & 475 & 95 & 2 & .4 & 23 & 4.6 \\
\hline 12-Multi-dose vials to be used for more than one patient. & 229 & 45.8 & 5 & 1 & 266 & $\overline{53.2}$ \\
\hline $\begin{array}{l}\text { 13-Multi-dose vials are dated by HCP when they are first } \\
\text { opened and discarded within the time period. }\end{array}$ & 217 & 43.4 & 4 & 0.8 & 279 & 55.8 \\
\hline 14-Presence of dirty sharps exposed nurses to NSI. & 53 & 10.6 & 8 & 1.6 & 439 & $\overline{87.8}$ \\
\hline 15-Immediate discarding of sharps in a sharp box. & 476 & 95.2 & 13 & 2.6 & 11 & 2.2 \\
\hline 16-Appropriate disposal / destruction of sharp S. & 485 & 97 & 10 & 2 & 5 & 1 \\
\hline 17-Bending of needles after use. & 5 & 1 & 3 & 0.6 & 492 & 98.4 \\
\hline 18-Used needle outside safety box. & 13 & 2.6 & 3 & 0.6 & 484 & 96.8 \\
\hline
\end{tabular}


Table (6): Comparison between nurses at the selected hospitals regarding their awareness, knowledge and practice injection safety $(\mathbf{n}=500)$

\begin{tabular}{|c|c|c|c|c|c|c|c|c|c|c|c|c|c|c|c|}
\hline \multirow{3}{*}{ Hospital name } & \multicolumn{4}{|c|}{ Awareness level } & \multirow{3}{*}{$\begin{array}{c}\text { p. } \\
\text { valu } \\
\text { e }\end{array}$} & \multicolumn{4}{|c|}{ Knowledge score } & \multirow{3}{*}{$\begin{array}{l}\text { p.va } \\
\text { lue }\end{array}$} & \multicolumn{4}{|c|}{ Practice score } & \multirow{3}{*}{$\begin{array}{l}\text { p. } \\
\text { val } \\
\text { ue }\end{array}$} \\
\hline & \multicolumn{2}{|c|}{ Good } & \multicolumn{2}{|c|}{ Poor } & & \multicolumn{2}{|c|}{ Satisfactory } & \multicolumn{2}{|c|}{$\begin{array}{c}\text { Un } \\
\text { satisfactory }\end{array}$} & & \multicolumn{2}{|c|}{ Good } & \multicolumn{2}{|c|}{ Poor } & \\
\hline & N. & $\%$ & $\mathbf{N}$ & $\%$ & & N. & $\%$ & $\mathbf{N}$. & $\%$ & & N. & $\%$ & N. & $\%$ & \\
\hline $\begin{array}{l}\text { General Aleman } \\
\text { Hospital } \\
(\mathrm{n}=120)\end{array}$ & 116 & 23.2 & 4 & 0.8 & \multirow[t]{6}{*}{1.88} & 66 & 55 & 54 & 45 & \multirow[t]{6}{*}{$\begin{array}{l}0.00 \\
1 * *\end{array}$} & $\begin{array}{l}9 \\
1\end{array}$ & $\begin{array}{c}75 . \\
8\end{array}$ & 29 & 24.2 & \multirow{6}{*}{$\begin{array}{l}0.0 \\
01 \\
* *\end{array}$} \\
\hline $\begin{array}{l}\text { Assiut Fever } \\
\text { Hospital }(n=96)\end{array}$ & 96 & 19.2 & 0 & 0.00 & & 46 & 47.9 & 50 & 52.1 & & $\begin{array}{l}4 \\
9\end{array}$ & 51.0 & 47 & 49.0 & \\
\hline $\begin{array}{l}\text { Chest } \\
\text { hospital(n=100) }\end{array}$ & 98 & 19.6 & 2 & 0.4 & & $\begin{array}{l}6 \\
7\end{array}$ & 67 & 33 & 33 & & $\begin{array}{l}6 \\
9\end{array}$ & 69 & 31 & 31.0 & \\
\hline $\begin{array}{l}\text { General Assiut } \\
\text { Hospital(n=105) }\end{array}$ & 104 & 20.8 & 1 & 0.2 & & 76 & 72.4 & 29 & 27.6 & & $\begin{array}{l}5 \\
9\end{array}$ & 56.2 & 46 & 43.8 & \\
\hline $\begin{array}{l}\text { Hospital of } \\
\text { Ophthalmology( } \\
n=79)\end{array}$ & 79 & 15.8 & 0 & 0.00 & & 62 & 78.5 & 17 & 21.5 & & $\begin{array}{l}7 \\
9\end{array}$ & $\begin{array}{c}10 \\
0\end{array}$ & 0 & $0.0 \%$ & \\
\hline Total(n=500) & 493 & 98.6 & 7 & 1.4 & & 317 & 63.4 & 183 & 36.6 & & 347 & 69.4 & 153 & 30.6 & \\
\hline
\end{tabular}

Table(1): Showed that: The majority of nurses were female, their age ranged from 20-30 years, married, technician, and their experience from a year to 5 years $(88.0 \%, 62 \%, 76.0 \%, 43.0 \%$, and $41.0 \%$ respectively), regarding their training the majority had training about safety injection, and infection control (76.4\% and $92.8 \%$ ) respectively.

Table (2): Shows that, $(86.8 \%)$ of nurses received hepatitis B vaccination, (78.2\%) didn't have NSIs in the last six months, and $(70.2 \%)$ did not record that they had a NSIs.

Table(3): Mentioned that; Nearly all nurses were aware about using syringe and needle for only one patient, hand washing before injection, discarding the used syringe and needle in a safety container and avoiding recapping of needles after giving injection (98\%, 97\%, 96.8\% and $88.2 \%$ respectively).It was found that nurses were aware about not bending needles after use, preventive approaches of NSI and use of gloves while giving injections $(95 \%, 95 \%$ and 93\% respectively).

Table(4): Illustrated that, More than half of nurses had poor knowledge about definition of unsafe injection and definition of injection safety $(60.8 \%$ and 53.8\%). Also nurses had good knowledge on possible causes of NSI and diseases transmitted by NSI $(41 \%$ and $40.4 \%)$. Most of them had poor knowledge on measures to be taken after NSI but they had good knowledge on preventive measures from NSI $(37.6 \%, 35.6 \%)$.

Table (5): Mentioned that; The majority of nurses were appropriately disposaling of sharps, immediate discarding of sharps in sharp box, needles and syringes are used for only one patient, medication vials are entered with a new needle, injections are prepared using aseptic technique, reading the label over medication vial or ampoule, wearing gloves before injection, using two hands recapping (97\%,
$95.2 \%, 95.2 \%, 95 \%, 86 \%, 67.8 \%, 61.6 \%$ and $55 \%$ respectively).

Majority of nurses didn't do the following practice including: bending of needles after use, the used needle outside safety box, presence of dirty sharps exposed nurses to NSI, aspirating drug from ampoule A. filling around the neck of the ampoule? B. Ampoule covered with gauze piece, disinfected the rubber septum on a medication vial with alcohol prior to piercing, dating multi-dose vials by HCP when they are first opened and discarded within the time period, washing hands before and after injection, using of multi-dose vials for more than one patient, disinfection of area was done with alcohol swab by using inward to outward direction, $(98.4 \%$, $96.8 \%, 87.8 \%, 87.6 \%, 87 \%, 55.8 \%, 5.2 \%, 54.2 \%$, $53.2 \%$ and $48.5 \%$ ).

Table (6): Shows that, there were no significance statistical differences between the nurses at five hospitals regarding awareness level and there were statistical significant differences between them regarding (knowledge and practice) scores.

\section{Discussion}

Based on the results of the present study, the majority of the nurses their age was from 20 to 30 years, married, females, had diploma of nursing, and the majority of them had infection control training. This study result was in the same line with the study of Moussa \& Shahin, (2015) entitled as "Evaluation of an educational program on nurses' knowledge and practice regarding standard precautions of infection control measures in outpatients clinics". According to work experience, more than one third of the nurses were having less than 5years of service experience. This study result disagreed with Onyemocho et al., (2013) in their study entitled as "knowledge and practices of injection safety among workers of 
Nigerian Prison services health facilities in Kaduna State" when they said that; large proportion of nurses had 6 years of experience.

Concerning training on injection safety, more than two thirds had prior training. This result was in the same line with Khurram et al., (2011) in their study entitled as "Needle stick injuries: a survey of doctors working at tertiary care hospitals of Rawalpindi" who reported that; most of the injection providers had been sent for training on safe injection practice. Regarding vaccination against hepatitis $\mathrm{B}$, more than two thirds of nurse had received vaccination against hepatitis B. This study was in the same line with Gurung et al., (2010) \& Khurram et al., (2011) who stated that; more than two thirds of the nurses received vaccination against Hepatitis $B$.

It was alarming that; more than two thirds of nurses were still not reporting NSI to the hospital administration. This finding was consistent with a study in hospitals of Polkhara and Nepal done by Kaphle et al., (2014) who revealed that; majority of nurses did not reporting NSI to the hospital administration also Foda et al., (2017) who conducted a study entitled as " Safe injection procedures, injection practices, and needle stick injuries among health care workers in operating rooms in Alexandria University, Egypt" told that; majority of nurses did not report their exposure of NSI. On the other hands, these findings are in opposition to the results of a study were done by El Tawil ,(2016) in Al jouf region, Saudi Arabia, who reported that; more than two thirds of nurses had reported NSI and took post-exposure medication .

Regarding awareness level, the current study showed that nearly all nurses were aware that needle should be discarded after use, this finding is similar with the study conducted in hospital of Kolkata, and West Bengal, India by Paul et al., (2011) who stated that; majority of nurses correctly mentioned needle should be discarded after use. The data illustrate that majority of nurses were aware about hand washing proceeding injection practice as in Bhardari , (2008) in a study entitled as " Safe injection practices and awareness among health care workers in tertiary level hospitals Kathmandu" who found that; more than two thirds of nurses were aware about the importance of hand washing procedure. Regarding sharps disposal after use, most of nurses were aware about appropriate disposal after use, this finding was contradicted with the study entitled as "Assessment of Knowledge and Practices on Injection Safety among Service providers in east Godavari District of Andhra Pradesh' 'carried out by Garapati \& Peethala., (2014) who stated that; only quarter of the sample were having knowledge about correct disposal of sharps.

The current study showed that; more than two thirds of nurses were aware of don't recapping needle after giving injection. Similar result was presented in a study from Surat by Naik et al., (2012) where half of the study sample were aware of it.

The study was done by Hauri et al., (2008) also suggested that; avoiding needle recapping and other hand manipulation are essential to prevent NSIs. Two handed recapping of the needle should be avoided as it is the most common cause of NSIs encountered. This high rate of recapping suggests that; health workers need training on injection safety.

Regarding nurses knowledge about definition of safe and unsafe injection; more than half of nurses didn't know the right meaning of safe and un safe injection. In contrast a study was done by Onyemocho et al., (2013) and reported that; most participants knew the correct definition of them. Regarding disease transmitted through unsafe injections; more than one third of nurses gave right answer about if HIV/AIDS, Hepatitis B, \& C could be transmitted through unsafe injections, similar finding in the study conducted by Omorogbe et al., (2012) entitled as " Injection safety practices among nursing staff of mission hospitals in Benin City, Nigeria".

This study result was supported by a study conducted in a tertiary care hospital of Pakistan by Siddique et al., (2008) who stated that; third of the sample reported that the most common cause of NSI was recapping of needle. Similarily, a study from Pokhara, Nepal revealed that; more than quarter of the nurses at NSIs were due to recapping of needle. The data revealed that; more than one third of the nurses knew the preventive approaches of NSI which is comparatively lower with the study conducted among nurses in East Go jam Zone Health Institutions, Ethiopia which was conducted by Aderaw ,(2013) who said that; only few nurses knew the preventive measures after getting NSI where in a study conducted in Khanevedeh Hospital in Tehran by Galougahi, (2013) that reported nurses knew it. Also a study conducted in health centers in El-Minia Governorate in Egypt by Hosseion, (2015) and told that; there is a risk of acquiring blood-borne infections through a lack of adequate knowledge among these nurses about the consequences of NSIs. On observation during the study the researcher found that, more than half of nurses didn't practice regular hand washing with water and soap before and after administering injection. In contrast to a study was done by Omorogbe et al., (2012) who showed that; more than two thirds of nurses were practicing regular hand washing with water and soap and Paul et al., (2011) said that; only less than quarter of nurses were practicing hand washing with soap and water. The finding of this study was in agreement with the study conducted by Onyemocho et al., (2013) \& Hosseion, (2015) where more than two 
thirds of nurses didn't wash their hands before and after administring injection. This study was found that; most of nurses had a good knowledge about hand washing, but during observation it was found that; only less than quarter of nurses washed their hands before and more than quarter of them washed their hands after injecting correctly. This result was in the same line with a study conducted by Foda et al., (2017) who said that; more than half of the sample didn't wash their hands before and after giving injection.

Regarding rubber septum of multi-dose vial cleaning with alcohol before withdrawing drug from vials, in this study more than two third of nurses didn't perform this step in injections. In contrast a study entitled as" An observational Study of Safe Injection Practices in a Tertiary Care Teaching Hospital" was done by Mehta et al., (2016) who reported that; more than one third of the nurses did this step in injections procedure.

This study showed that; more than half of nurses used to practice two handed recapping of needle and more than half still recap needles all the time after use. This finding was contradictory with a study conducted by Onyemocho et al., (2013) where more than two thirds of participants didn't recap needle after use.

A study based on self-reported practice conducted in Western Regional Hospital Bokhara by Gurung et al., (2010) showed that more than two thirds of nurses recap needle after use. Study was done at Nigeria by Obi \& ofilli (2013) entitled as" Injection Safety Practices among Medical Doctors in a Tertiary Health Institution in South, Nigeria"and documented that; more than two thirds of the healthcare providers were engaged in two handed recapping after injection. Paul et al., (2011) reported that; only more than one third of participant recap needle. A similar situation was also observed in a studies were done by Oladimeji et al., (2012) \& El Tawil,(2016) in Al jouf region, Saudi Arabia showed that; most of respondents practice were recapping of needle after use. This practice of recapping and detaching of needles increase the risk of NSIs among the nurses.

Regarding safe handling and disposal of sharps most of nurses strictly adhered to minimizing accidental NSIs and immediate discarding of sharps like cut needle and syringes in non-compressible sharp box in nearly all nurses. This finding was contradictory with the study of Kaphle et al., (2014) who illustrated that; two third of nurses didn't follow that, also Hossion, (2015) said that; the minority of nurses sometimes use protective measures, and practice proper disposal of sharp and always recap needles . The current study reported that, nearly all nurses' did not bended needles after giving injection and collecting syringe and needles in safety box. This study was in accordance with a study conducted by Kaphle et al., (2014) entitled as "Awareness and Practices on Injection Safety among Nurses Working in Hospitals of Pokhara, Nepal " who stated that; no nurses were involved in such practice, as they always disposable syringe and needles in safety box.

The data illustrated that, there were no significance statistical differences between them regarding awareness level and there were statistical significant differences between the five hospitals regarding (knowledge and practice) scores. Also the majority of nurses had a good level of awareness regarding injection safety but in their practical level were not in the same level, this was supported by Mehta et al., (2016) who mentioned that; knowledge and practice of health care providers were nearly up to mark.

Finally, Unsafe handling practices of needles prior to disposal (e.g. two-hand recapping) were more frequent among all health-care workers where twohand recapping of needles was the commonest cause of such injuries and there was no significant difference between those who had received training and those who had not. Nurses who were exposed to NSIs reported that; they did not do anything at all after exposure. Only a small proportion reported that they took a vaccination against $\mathrm{HBV}$ infection as soon as possible after the injury. Hand washing was the commonest reported action taken by health-care workers who suffered a NSIs. Furthermore, after NSIs, health-care workers who were injured did not deal properly with their injuries.

\section{Conclusion}

Based on the results of the present study, it can be concluded that:

1. Majority of the nurses had a good level of awareness regarding injection safety but less than half had unsatisfactory knowledge and the practical injection safety precautions were not followed properly.

2. The study revealed that the studied nurses had average level of awareness about injection safety but there is gap on their knowledge and practices, most of participant's service experience was less than 5 years, which may be one of the causes for poor practices.

3. This study showed that most healthcare workers (HCWs) followed the proper injection protocols but performed some mistakes that exposed them and the community to the risk of NSIs and blood borne infections example; washing hands, wearing/changing gloves, repeated handling of sharps like needle, wiping of needle with swab and breaking of ampoule with solid object. 


\section{Recommendations}

Based on the findings of the present study, the following recommendations are derived:

1. An immediate training and awareness program, refreshing courses and periodic workshops on injection safety to all nurses to increase awareness and their knowledge which will reflect on their practice while working with patients for reducing the high rate of NSIs and the unsafe practices like reusing, recapping, bending, inappropriate collection and disposal syringe and needles.

2. It should be mandatory for to all employees in every hospital to get immune-prophylaxis against Hepatitis B before entering into clinical setting.

3. Reporting of NSI is mandatory to higher officials of infection control committee; regular screening of nurses and laboratory technicians for infections transmitted through contaminated needles should be done on regular intervals.

\section{For further research}

1. Prepare nursing educational program about injection safety to prevent mistakes that expose nurses and the community to the risk of NSIs and blood borne infections.

2. Replication of the study on a large probability sample acquired from different geographical areas in Egypt to figure out the main aspects of this problem.

\section{References}

1. Abdul Aziz, A., Esena, R., \& DotseGborgbortsi, W., (2013): Assessment Of Injection Safety Practices In Health Facilities In Bongo And Talensi Districts In The Upper East Region Of Ghana: Part 1-Injection Safety Practices. Int J Sci Techno Res, 11, Pp. 347-58.

2. Aderaw Z., (2013): Assessment on magnitude of needle stick and sharp injuries and associated factors among healthcare workers in East Gojjam zone health institutions, Amahara Regional State,Ethiopia. Global journal ofmedical research; 13(3):P.419.

3. AL-Rawajfah, O., (2016): Infection control practices among intensive care unit registered nurses: a Jordanian national study. Nursing in critical care, 21(2), Pp. 20-27.

4. Bhandari T., (2008): Safe injection practices and awareness among health care workers in tertiary level hospitals Kathmandu NHRC; 6(12):Pp.2227.

5. Chowdhury, A., Roy, T., Faroque, A., Bachar, S., Asaduzzaman, M., Nasrin, N., \& Anderson, C., (2011): A comprehensive situation assessment of injection practices in primary health care hospitals in Bangladesh. BMC public health, 11(1), P.779.
6. Drechsel, P., Mahjoub, O., \& Keraita, B., (2015): Social and cultural dimensions in wastewater use. In Wastewater, Pp. 7592.Springer Netherlands.

7. El Tawil A., (2016): Knowledge and prevalence of needle stick injuries among nurses working in hemo dialysis units in Al jouf region, Saudi Arabia, 5(6), Pp 13-19.

8. Foda, N., Elshaer, N., \& Sultan, Y., (2017): Safe injection procedures, injection practices, and needle stick injuries among health care workers in operating rooms. Alexandria Journal of Medicine Available on line 10 january, 2017.

9. Galougahi M., (2013): Evaluation of Needle sticks injuries among nurses of Khanevadeh Hospital in Tehran. JNMR;15(4):P.1

10. Garapati S., \& Peethala S., (2014): Assessment of Knowledge and Practices on Injection Safety among Service providers in east Godavari District of Andhra Pradesh,India, Journal of community Health ,26(3),Pp. $259-263$.

11. Gurung N., Paudel K., \& Pun C., (2010): Needle sticks injuries among health care workers in a tertiary care teaching hospital, Pokhara, Nepal. Journal of Gandaki Medical College; 3(1):Pp.47:50.

12. Hanafi M., Mohamed A., Kassem M., \& Shawki M., (2011): Needle stick injuries among healthcare workers of University of Alexandria hospitals.EMHJ ;

13. Hauri A., Armstrong G., \& Hutin Y., (2008): Contaminated injections in health care settings in comparative quantification of health risks. Global and regional burden of disease attributable to selected major factors,

14. Hosseion E.,(2015): Standard precaution and incidence of needle stick injury during children vaccination among nurses working in maternal and child health centers in El-Minia Governorate, International Journal of Advanced Nursing Studies, 4 (1), Pp 1-6.

15. Kaphle H., Jain V., Paudel P., Subedi S., Poudal S., \& Gupta N., (2014): Awareness and Practices on Injection Safety among Nurses Working in hospitals of polkhara ,Nepal ,international journal of medical and health sciences, (http://www.ijmhs.net) ,3(4): P.301-303

16. Khurram M., Ijaz K., Bushra T., Khan Y., Bhushra H., \& Hussain W., (2011): Needle sticks injuries: a survey of doctors working at tertiary care hospitals of Rawalpindi. J Pakistan Med Asso.; 61:Pp.63-65

17. Martin, W., Lippitt, J., \& Prothero, T., (2013): Hazardous waste handbook for health and safety. Butterworth-Heinemann,P. 288. 
18. Mehta D., Pillai A., \& Singh A., (2016): An observational Study of Safe Injection Practices Injection Practices in a Tertiary Care Teaching Hospital , International Journal of applied research;2(5):Pp.733:737

19. Moussa M., \& Shahin S., (2015): Evaluation of an educational Program on nurses'knowledge and practice regarding Standard precautions of infection control measures in outpatients clinics, International Journal of Advanced Research, 3(6), Pp.1024-1034.

20. Naik A., Gharat V., \& Bansal R., (2012): An assessment of injection practices in urban health centres of Surat City: Are the health workers safe? National Journal of Community Medicine; 3(1):Pp.125-128.

21. Njiru, M., Mutai, C., \& Gikunju, J., (2013): Awareness and Practice on Biomedical Waste Management among Health Care Personnel in Kenyatta National Hospital. East African medical journal, 90(2), Pp.52-58.

22. Obi, A., \&Ofili, A., (2013): Injection Safety Practices among Medical Doctors in a Tertiary Health Institution in South Southern, Nigeria. IOSR Journal of Denta 1 and Medical Sciences, 8, Pp. 42:49.

23. Oladimeji A., Adekunle G., Sunday A., Omotoso I., Tanimola M., \& James O., (2012): Injection Safety Practices among Primary health care workers in Ilorin, kwara state of Nigeria,Health Science Journal(Hsj),6(3):Pp.496:508.

24. Omorogbe V., Omuemu V., \& Isara A., (2012) Injection safety practices among nursing staff of mission hospitals in Benin City, Nigeria. Ann Afr Med 11: Pp.36:41

25. Onyemocho A., Joshua I., \& Enokela O., (2013): knowledge and practices of injection safety among workers of Nigerian Prison services health facilities in Kaduna State. American journal of public health research 1:Pp. 171:176.

26. Paul B., Roy S., Chattopadhyay D., Bisol S., Misra R., Bhattacharya N., (2011): A study on safe injection practice of nursing personnel in a tertiary care hospital of Kolkata, West Bengal, India. TAF Prev Med Bull ; 10(6):Pp.681:686

27.Sam, T., (2016): Developing Drug Administration Devices for Geriatric Use. In Developing Drug Products in an Aging Society, Pp. 403-446.

28. Siddique K., Mirza S., Fizza S., Anwar T., \& Malik A., (2008): Knowledge, attitude and practice regarding needle stick injuries amongst health care workers .Pakistan Journal of Surgery 2008; 24(8): Pp. 243-248.
29. Tandon, N., Kalra, S., Balhara, Y., Baruah, M., Chadha, M., Chandalia, H., \& Shukla, R., (2017): Forum for injection technique and therapy expert recommendations, India:The Indian recommendations for best practice in insulin injection technique, 2017. Indian Journal of Endocrinology and Metabolism, 21(4), P. 600.

30. Thrift, A., El-Serag, H., \&Kanwal, F., (2017): Global epidemiology and burden of $\mathrm{HCV}$ infection and HCV-related disease. Nature Reviews Gastroenterology \& Hepatology , 14(2), Pp. 122-132.

31. Wendland, C., (2012): Moral maps and medical imaginaries: clinical tourism at Malawi's college of medicine American Anthropologist, 114(1), Pp. 108-122. 